\title{
OPEN The effect of lack of ANC visit and unwanted pregnancy on home child-birth in Ethiopia: a systematic review and meta-analysis
}

Yitayish Damtie ${ }^{1 凶}$, Bereket Kefale $^{1}$, Melaku Yalew ${ }^{1}$, Mastewal Arefaynie ${ }^{1}$, Elsabeth Addisu $^{1}$, Tesfaye Birhan ${ }^{1}$, Nigus Cherie ${ }^{1}$, Bezawit Adane ${ }^{2}$, Wolde Melese ${ }^{2}$, Gedamnesh Bitew ${ }^{2}$, Erkihun Tadesse ${ }^{2}$, Reta Dewau ${ }^{2}$ \& Atsedemariam Andualem ${ }^{3}$

Although extensive efforts were made to improve maternal and child health, the magnitude of home child-birth is considerably high in Ethiopia. Therefore, this meta-analysis aimed to estimate the effect of lack of ANC visit and unwanted pregnancy on home child-birth among reproductive-age women in Ethiopia. International databases, including Cochrane Library, Google Scholar, PubMed, Global Health, HINARI, and CINAHL were searched systematically to identify studies reporting the prevalence of home child-birth and its association with lack of ANC visit and unwanted pregnancy among reproductive-age women in Ethiopia. STATA/SE version-14 was used to analyze the data and Der Simonian and Liard's method of random effect model was used to estimate the pooled effects. The heterogeneity between study and publication bias was assessed by using I-squared statistics and Egger's test respectively. A total of 19 studies with 25,228 study participants were included in this meta-analysis. The pooled prevalence of home child-birth among reproductive-age women in Ethiopia was $55.3 \%$. Sever heterogeneity was exhibited among the included studies $\left(I^{2}=99.8, p=0.000\right)$. The odds of home child-birth among mothers who have no ANC visit was 3.64 times higher compared to their counterparts $[\mathrm{OR}=3.64,95 \%, \mathrm{Cl}:(1.45,9.13)]$. There was significant heterogeneity among the included studies $\left(I^{2}=94 \%, p=0.000\right)$. However, there was no statistical evidence of publication bias in the pooled effect of lack of ANC visit on home child-birth $(P=0.302)$. Women who experienced unwanted pregnancy were 3.02 times higher to give birth at home compared to women with a wanted pregnancy $[\mathrm{OR}=3.02,95 \% \mathrm{Cl}:(1.19,7.67)]$. Severe heterogeneity was exhibited $\left(\mathrm{I}^{2}=93.1 \%, \mathrm{p}=0.000\right)$ but, there was no evidence of significant publication bias in the pooled effect of unwanted pregnancy on home child-birth $(P=0.832)$. The proportion of home child-birth among reproductive-age women in Ethiopia remains high. Lack of ANC visit and unwanted pregnancy had a significant effect on the practice of home child-birth. Strengthening behavioral change communication programs should be the primary focus area to improve institutional delivery service utilization among women with lack of ANC visit and unwanted pregnancy.

\author{
Abbreviations \\ ANC Antenatal care \\ EDHS Ethiopia demography and health survey \\ HSTP Health sector transformation plan \\ IEC Information, education and communication \\ IESO Integrated emergency obstetrics and surgery \\ JBI Joana Brigg's institute \\ MMR Maternal mortality ratio
}

\footnotetext{
${ }^{1}$ Department of Reproductive and Family Health, School of Public Health, College of Medicine and Health Sciences, Wollo University, Dessie, Ethiopia. ${ }^{2}$ Department of Epidemiology and Biostatistics, School of Public Health, College of Medicine and Health Sciences, Wollo University, Dessie, Ethiopia. ${ }^{3}$ Department of Adult Health Nursing, School of Nursing and Midwifery, College of Medicine and Health Sciences, Wollo University, Dessie, Ethiopia. ${ }^{\circledR}$ email: yitutile@gmail.com
} 
PRISMA Preferred reporting items for systematic reviews and meta-analysis

SBA Skilled birth attendants

SDG Sustainable development goal

SSA Sub-Saharan African

WDA Women development army

Each year, an estimated 303,000 women die as a result of preventable pregnancy and childbirth complications worldwide ${ }^{1}$. Ninety-nine percent $(99 \%)$ of the global maternal deaths occur in developing countries and SubSaharan African (SSA) countries alone shared $62 \%$ of all maternal deaths. Ethiopia is the fourth top ten countries in the world with the highest-burden of maternal mortality next to India, Nigeria, and the Democratic Republic Congo sharing $58 \%$ of all the global deaths ${ }^{1}$. The 2016 Ethiopia Demography and Health Survey (EDHS) report showed that the Maternal Mortality Ratio (MMR) in the country was 412/100,000 live births ${ }^{2}$.

More than two-thirds (73\%) of maternal deaths occur during childbirth and within $24 \mathrm{~h}$ post-partum period due to direct obstetric causes such as hemorrhage, infection, obstructed labor, hypertension, and abortion ${ }^{3}$. Hypertensive disorders of pregnancy, hemorrhage, and sepsis alone accounted for more than $50 \%$ of all maternal mortality worldwide ${ }^{4}$.

One-third of births worldwide happen at home in the absence of SBA ${ }^{5}$. Studies have shown that home delivery ranged from $65 \%$ in Tanzania to $87.7 \%$ in Bangladesh ${ }^{6}$. The situation is worst in Africa in which more than $60 \%$ of women deliver at home without SBAs in contrary to less than $1 \%$ in developed nations ${ }^{7}$.

In Ethiopia, the prevalence of home delivery ranged from $19.1 \%$ in Shashemene town ${ }^{8}$ to $80 \%$ in Sherkole district of Benishangul Gumuz region ${ }^{9}$. According to the 2016 EDHS report, the prevalence of home delivery in the country was 73\%, ranging from 3\% in Addis Ababa to $85 \%$ in Afar region ${ }^{2}$.

In the last fifteen years, the Ethiopian government has established an inspiring framework for improving maternal and child health like training and deploying Health Officers with a master of Integrated Emergency Obstetrics and Surgery (IEOS) program, establishing Women Development Army (WDA), and creating pregnant women conferences to enable them to discuss issues related with pregnancy and delivery, constructing maternity waiting home at health facilities, availing traditional ambulances and increasing the number of modern ambulances for early referrals of emergency cases ${ }^{10}$. Regardless of these efforts, the rate of home delivery is considerably high in Ethiopia ${ }^{2}$.

Lack of ANC visits is the most fundamental and proximal factor responsible for the high rates of home delivery in developing countries like Ethiopia ${ }^{11-14}$. The World Health Organization (WHO) strongly emphasizes the need to have at least four ANC, in which the first visit should be started during the first trimester ${ }^{15}$. Although quality ANC strongly influences the use of skilled delivery care ${ }^{16-18}$, only $43 \%$ of women attended four or more ANC visits in Ethiopia ${ }^{19}$ which is far from the national target (increasing four or more ANC visits to $95 \%$ by the year 2020 $)^{20}$. Unwanted pregnancy is another major contributing factor affecting home childbirth ${ }^{21,22}$. A study showed that it increases the rate of home delivery by $40 \%{ }^{23}$.

Reducing home delivery and increasing institutional delivery service utilization has a substantial contribution to the success of Sustainable Development Goal (SDG) 3 which aimed to reduce the global MMR below 70 per100, 000 live births by $2030^{24}$, and the Ethiopian Health Sector Transformation Plan (HSTP) IV which aimed to decrease the national MMR to 199 per 100,000 live births by $2020^{20}$.

Different studies were conducted to assess the practice of home child-birth in Ethiopia ${ }^{8,9,15,25-40}$. A systematic review and meta-analysis was also done ${ }^{41}$. However, the authors included those articles assessing institutional service utilization in their study which cannot indicate the exact figure of the prevalence of home delivery. They also included those studies assessing the intention of women towards the place of delivery that didn't clearly show the actual place of delivery. Moreover, they couldn't assess the effect of unwanted pregnancy on home delivery although it is the major factor that affects the rate of home child-birth in the Ethiopian context. Therefore, this study aimed to estimate the effect of lack of ANC visit and unwanted pregnancy on home child-birth among reproductive-age women in Ethiopia. The result of this meta-analysis will help to identify whether the absence of ANC follow-up and unwanted pregnancy affect home delivery practice in Ethiopia and to reduce unwanted pregnancy by improving family planning utilization and promote the importance of ANC visit through information communication education and behavioral change communication programs accordingly.

\section{Materials and methods}

Searching strategy. The current systematic review and meta-analysis was organized according to the Preferred Reporting Items for Systematic Reviews and Meta-Analysis (PRISMA-2009) guideline ${ }^{42}$ (see supplementary file 1). International databases including Cochrane Library, Google Scholar, PubMed, Global Health, HINARI, and CINAHL were searched systematically to estimate the pooled prevalence of home child-birth and its association with lack of ANC visit and unwanted pregnancy among reproductive-age women in Ethiopia. The searching was carried out from September 1 up to December 30, 2020, by two authors (YD and BK) independently, and research articles published from 2000 up to December 30, 2020, were included in the analysis.

All the relevant studies were identified by using the following search terms: "proportion", "magnitude", "prevalence", "incidence", "home delivery", "home birth", "home child-birth", "risk factors", "predictors", "factors", "determinants", "associated factors", "women", " mothers", " Reproductive Age Women", " women of child bearing age", "Ethiopia" using Boolean operators "OR" or "AND" (see supplementary file 2). The protocol of this meta-analysis was not registered on the International Prospective Register of Systematic Reviews (PROSPERO). 


\section{Eligibility criteria Inclusion criteria.}

Population: This systematic review and meta-analysis include studies conducted among women aged from1549 years in Ethiopia.

Exposure: ANC unbooked women and women with an unwanted pregnancies.

Comparison: women who have ANC follow-up and women with a wanted pregnancy.

Outcome: Studies assessed home child-birth as a primary outcome.

Study design: all types of observational studies (Cross-sectional, case-control, and cohort) were included.

Country: studies conducted only in Ethiopia.

Study setting: all facility and community-based studies.

Time frame: studies published from the beginning of 2000 up to December 30, 2020.

Publication: both published and unpublished articles.

Language: studies written in the English language were included in this study.

Exclusion criteria. Those studies which are purely qualitative, the outcome of the interest not reported, and those with the absence of full text were excluded from this study after two email contacts of the corresponding author.

Outcome measurement. This systematic review and meta-analysis measure three main outcomes. The primary outcome of this study was the pooled prevalence of home child-birth which was calculated from each primary article by dividing the number of women delivered at home to the total sample size multiplied by 100 .

The second outcome was the association between lack of ANC visit and home child-birth. In this study, using ANC was considered if women received at least one ANC visit and more during the period of pregnancy. The third outcome of this study was the association between unwanted pregnancy and home child-birth. Unwanted pregnancy was defined as a pregnancy that occurred when no more children were desired. For the second and the third outcomes, the association between predictor variables (lack of ANC visit and unwanted pregnancy) and home child birth was determined in the form of the log odds ratio.

Data extraction and quality assessment. After duplicate files were removed by endnote software, three reviewers (MY, NC, and MA) independently screened the leftover articles for inclusion. Then, based on their study design, the quality of the screened articles was assessed using Joana Brigg's Institute (JBI) critical appraisal checklist $^{43}$. In this study, all of the included articles scored $50 \%$ and more, thus all are included in the review. A group of two authors (EA and BA) assessed the quality of each article independently and the disagreement or the difference in the results at the time of quality assessment was resolved by taking the mean score of the results of both reviewers.

All the relevant data were extracted by using a standardized data extraction sheet. The data extraction sheet includes the following variables; the name of the first author, region, year of study, publication year, study setting (whether it is institution or community based), study area, study design, the prevalence of home child-birth, sample size, response rate, the residence of the mother, number women delivered at home and frequencies of lack of ANC visit and unwanted pregnancy in the form of a two by two tables. Five reviewers (TB, ET, GB, WM, and AA) extract all the necessary data independently and the disagreement raised at the time of data extraction was resolved by consensus.

Data analysis. All the necessary data were extracted using Microsoft Excel and exported to STATA version-14 for analysis. DerSimonian and Liard's method of random effect model ( $p$-value $<0.05)$ was used to calculate the pooled prevalence of home child-birth in Ethiopia ${ }^{44}$. Besides, pooled odds ratios with $95 \%$ confidence intervals was used to determine the association of home child-birth with lack of ANC visit and unwanted pregnancy.

The variation among the original articles was statistically estimated by using the $\mathrm{I}^{2}$ test. $\mathrm{I}^{2}$ tests $>75 \%$ was considered as severe heterogeneity and was subjected to subgroup and univariate Meta-regression analyses to identify the possible source of variations among the point estimates of the individual studies. Moreover, the funnel plot and egger's regression test at a p-value less than 0.05 was used to assess the presence of publication bias ${ }^{45}$.

\section{Results}

Study selection. The review identified a total of 1,396 published and unpublished articles by searching international databases; Cochrane Library, Google Scholar, PubMed, Global Health, HINARI, and CINAHL. Then, 1,365 articles were removed due to duplication and as a result of their titles and abstracts. The rest 31 articles were critically assessed based on the eligibility criteria and finally, a total of 19 full-text articles were included in this meta-analysis (Fig. 1).

Characteristics of the included studies. A total of nineteen studies ${ }^{8,9,15,25-40}$ with 25,228 study participants were included to estimate the pooled prevalence of home child-birth and its association with lack of ANC visit and unwanted pregnancy in Ethiopia. The sample size of the studies ranged from a minimum of 264 study participants from a study conducted in Abobo district, Gambella region ${ }^{33}$ to a maximum of 10,622 participants among a study conducted on 2016 EDHS data ${ }^{32}$. In this meta-analysis, seven regions from nine regions of the country were represented; six studies from SNNP $25,26,35,36,39,40$, four from Amhara ${ }^{28,30,31,34}$, three 


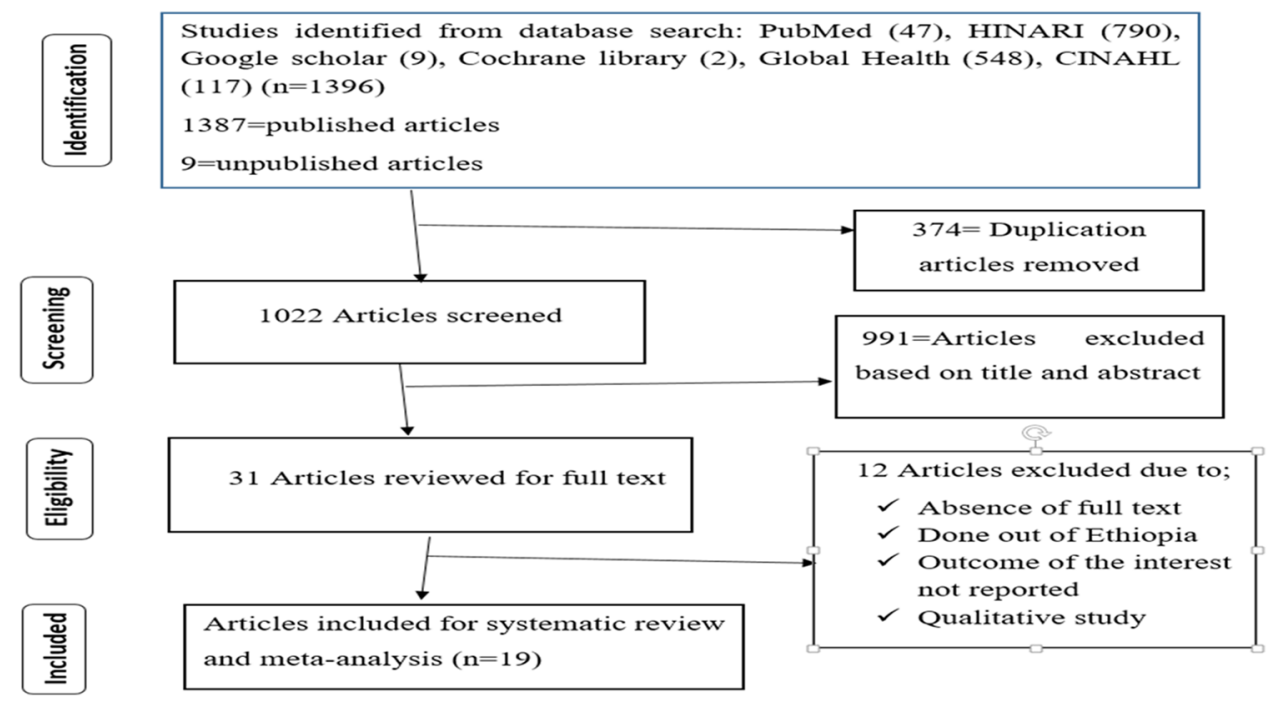

Figure 1. PRISMA flow diagram describing the selection of studies for systematic review and meta-analysis.

from Tigray ${ }^{29,37,38}$, one from Oromia ${ }^{8}$, one from $\mathrm{Afar}^{27}$, one from Benishangul Gumuz ${ }^{9}$ and one study from Gambella region $^{33}$. However, there were no studies reported from Hareri, and Somali regions. Regarding the study design, twelve studies were cross-sectional ${ }^{8,9,15,25-27,30-32,34,35,40}$, five were case-control ${ }^{28,29,33,36,37}$ and the rest two were cohort studies ${ }^{38,39}$. (Table 1).

Prevalence of home child-birth in Ethiopia. A meta-analysis of 14 studies showed that the pooled prevalence of home child-birth among reproductive-age women in Ethiopia was 55.3\% (95\% CI: 43, 67.5). As it was shown on the figure, DerSimonian and Laird random-effects meta-analysis model was used to estimate the pooled effect as a result of severe heterogeneity between the included studies $\left(\mathrm{I}^{2}=99.8, \mathrm{p}=0.000\right)$ (Fig. 2).

Publication bias was graphically assessed by using the funnel plot and there was an asymmetrical distribution of the effect estimates showing the presence of publication bias (Fig. 3), the eggers test statistics also evidenced that the presence of significant publication bias $(P=0.040)$. Duval and Tweedie's 'trim and fill' method was used to reduce and adjust the effect of publication bias ${ }^{46}$, and there was no significant variation in the newly estimated pooled prevalence as compared to the previous one.

Subgroup analysis and meta-regression. Subgroup analysis was conducted by region, residence, study design and sample size to identify the variation across the individual studies. Even though heterogeneity has still existed in the subgroup analysis of all the aforementioned parameters, the prevalence of home child-birth was significantly higher among studies conducted in rural settings [67.6\%, 95\% CI: $(52.6,82.6)]$ as compared to studies conducted in an urban setting. Similarly, the prevalence of home child-birth was significantly different among cross-sectional [60.9, 95\% CI: $(50.2,71.8)]$ and cohort studies $[21.1,95 \% \mathrm{CI}:(6.03,36.1)]$ (Table 2).

To identify the possible source of variation across the included studies, univariate meta-regression analysis was conducted using study-level characteristics (study year and sample size) as a cofactor, but none of them were found to be statistically significant (Table 3 ).

Factors associated with home child-birth. The effect of lack of ANC visit on home delivery was examined based on the results of seven studies ${ }^{8,9,27,28,33,36,38}$. The analysis revealed that women who have no ANC visit were 3.64 times more likely to deliver at home as compared to women who have ANC visit $[\mathrm{OR}=3.64,95 \%$, CI: $(1.45,9.13)]$. A random-effect meta-analysis model was employed to examine the association between lack of ANC visit and home delivery as a result of significant heterogeneity among the included studies $\left(\mathrm{I}^{2}=94 \%\right.$, $\mathrm{p}=0.000$ ) (Fig. 4).

Publication bias was assessed using both funnel plots and Egger's tests. Although the funnel plot seems asymmetric (Fig. 5), the result of Egger's test witnessed that there was no statistical evidence of publication bias in the pooled effect of lack of ANC visit on home child-birth $(\mathrm{P}=0.302)$.

A total of five studies were included to identify the association between unwanted pregnancy and home delivery ${ }^{28-30,33,37}$. The random-effect meta-analysis revealed that women who experienced unwanted pregnancy were 3.02 times more likely to give birth at home as compared to women with wanted pregnancy [OR $=3.02$, 95\%CI: $(1.19,7.67)]$. Sever heterogeneity was exhibited among the included articles $\left(\mathrm{I}^{2}=93.1 \%, \mathrm{p}=0.000\right)$ (Fig. 6).

There was no evidence of significant publication bias in the pooled effect of unwanted pregnancy on home delivery as it was indicated by Egger's tests $(\mathrm{P}=0.832)$ despite the asymmetrical distribution of the effect estimates on the funnel plot (Fig. 7). 


\begin{tabular}{|c|c|c|c|c|c|c|c|c|c|}
\hline Authors & $\begin{array}{l}\text { Publication } \\
\text { year }\end{array}$ & Region & Study Area & Study design & Sample size & Response rate & $\begin{array}{l}\text { No of women } \\
\text { delivered at } \\
\text { home }\end{array}$ & Prevalence (\%) & $\begin{array}{l}\text { Quality score } \\
(\%)\end{array}$ \\
\hline Ibrahim S et al..$^{25}$ & 2017 & SNNPR & Anlemo & Cross-sectional & 268 & 97.1 & 132 & 49.3 & 66.7 \\
\hline $\begin{array}{l}\text { Gistane Ayele } \\
\text { et al. }{ }^{26}\end{array}$ & 2015 & SNNPR & Arbaminch & Cross-sectional & 436 & 90.6 & 346 & 79.4 & 77.8 \\
\hline $\begin{array}{l}\text { Abdella M } \\
\text { et al. } .^{27}\end{array}$ & 2017 & Afar & Ayssaita & Cross-sectional & 317 & 99.7 & 225 & 71 & 77.8 \\
\hline Abebe et al. ${ }^{28}$ & 2012 & Amhara & Bahirdar & Case-control & 324 & 91 & - & - & 66.7 \\
\hline $\begin{array}{l}\text { Berhe and } \\
\text { Nigusie }^{9}\end{array}$ & 2020 & $\begin{array}{l}\text { Benishangul } \\
\text { Gumuz }\end{array}$ & Sherkole & Cross-sectional & 441 & 98 & 353 & 80 & 77.8 \\
\hline Tololu A et al. ${ }^{29}$ & - & Tigray & Central zone & Case-control & 300 & 95 & - & - & 66.7 \\
\hline Kasaye et al. ${ }^{30}$ & 2017 & Amhara & Debremarkos & Cross-sectional & 502 & 96.9 & 127 & 25.3 & 88.9 \\
\hline $\begin{array}{l}\text { Wodaynew } \\
\text { et al. } .^{31}\end{array}$ & 2018 & Amhara & Delanta & Cross-sectional & 557 & 96.7 & 196 & 35.2 & 88.9 \\
\hline $\begin{array}{l}\text { Chernet AG, } \\
\text { et al. }{ }^{32}\end{array}$ & 2019 & EDHS based & $\begin{array}{l}\text { EDHS } 2016 \\
\text { based }\end{array}$ & Cross-sectional & 10,622 & NR & 7137 & 67.2 & 88.9 \\
\hline Yebyo $\mathrm{H}$ et al. ${ }^{15}$ & 2015 & EDHS based & $\begin{array}{l}\text { EDHS } 2011 \\
\text { based }\end{array}$ & Cross-sectional & 7908 & NR & 6980 & 88.3 & 88.9 \\
\hline $\begin{array}{l}\text { Mekonnen Y } \\
\text { et al. }{ }^{34}\end{array}$ & 2015 & Amhara & Gozamin & Cross-sectional & 497 & 100 & 374 & 75.3 & 88.9 \\
\hline $\begin{array}{l}\text { DenekeDelibo } \\
\text { et al. } .^{55}\end{array}$ & 2020 & SNNPR & Badawacho & Cross-sectional & 531 & 96.2 & 391 & 73.6 & 88.9 \\
\hline $\begin{array}{l}\text { Wondimu and } \\
\text { Woldesemayat }\end{array}$ & 2020 & SNNPR & Hamar district & Case-control & 292 & 94.5 & - & - & 66.7 \\
\hline Tsegay et al. ${ }^{37}$ & 2017 & Tigray & Tanqua-Abergele & Case-control & 275 & 96.5 & - & - & 66.7 \\
\hline Gultie et al. $^{8}$ & 2016 & Oromia & \begin{tabular}{l|l} 
Shashemene \\
\end{tabular} & Cross-sectional & 277 & 97.2 & 53 & 19.1 & 66.7 \\
\hline $\begin{array}{l}\text { Hinsermu Bayu } \\
\text { et al. }{ }^{38}\end{array}$ & 2015 & Tigray & $\begin{array}{l}\text { Alamata, } \\
\text { Mehoni, and } \\
\text { Maichew }\end{array}$ & Cohort & 465 & 89 & 134 & 28.8 & 77.8 \\
\hline Siyoum et al. ${ }^{39}$ & 2018 & SNNPR & Wolaita & Cohort & 505 & 91.2 & 68 & 13.5 & 77.8 \\
\hline $\begin{array}{l}\text { Kucho and } \\
\text { Mekonnen }{ }^{40}\end{array}$ & 2017 & SNNPR & Zala & Cross-sectional & 447 & 100 & 302 & 67.6 & 77.8 \\
\hline $\begin{array}{l}\text { Asmelash Aber- } \\
\text { aMitiku et al. } .^{33}\end{array}$ & 2020 & Gambella & Abobo District & Case-control & 264 & 100 & - & - & 66.7 \\
\hline
\end{tabular}

Table 1. Descriptive summary of nineteen studies included in the meta-analysis of home child-birth and associated factors among pregnant women in Ethiopia, 2021. SSNPR-Southern Nations, Nationalities, and Peoples Region.

\begin{tabular}{|c|c|c|c|c|c|}
\hline Authors & $\begin{array}{l}\text { Study } \\
\text { year }\end{array}$ & & & ES $(95 \% \mathrm{Cl})$ & $\begin{array}{l}\% \\
\text { Weight }\end{array}$ \\
\hline Ibrahim s et al & 2017 & & & $49.25(43.27,55.24)$ & 7.07 \\
\hline Gistane Ayele et al & 2012 & & - & $79.36(75.56,83.16)$ & 7.15 \\
\hline Abdella $\mathrm{M}$ et al & 2016 & & - & $70.98(65.98,75.97)$ & 7.11 \\
\hline Berhe and Nigusie & 2018 & & - & $80.05(76.32,83.78)$ & 7.15 \\
\hline Kasaye et al. & 2016 & - & & $25.30(21.50,29.10)$ & 7.15 \\
\hline Wodaynew et al & 2018 & - & & $35.19(31.22,39.15)$ & 7.14 \\
\hline Chernet $A G$, et al. & 2018 & & $\bullet$ & $67.19(66.30,68.08)$ & 7.19 \\
\hline Yebyo $\mathrm{H}$ et al. & 2014 & & $\bullet$ & $88.27(87.56,88.97)$ & 7.19 \\
\hline Mekonnen $Y$ et al. & 2014 & & $\bullet$ & $75.25(71.46,79.05)$ & 7.15 \\
\hline Deneke Delibo et al & 2018 & & - & $73.63(69.89,77.38)$ & 7.15 \\
\hline Gultie et al. & 2015 & - & & $19.13(14.50,23.77)$ & 7.12 \\
\hline Hinsermu Bayu et al. & 2014 & - & & $28.82(24.70,32.93)$ & 7.14 \\
\hline Siyoum et al & 2017 & $\bullet$ & & $13.47(10.49,16.44)$ & 7.16 \\
\hline Kucho and Mekonnen & 2015 & & - & $67.56(63.22,71.90)$ & 7.13 \\
\hline \multicolumn{2}{|c|}{ Overall $(1$-squared $=99.8 \%, p=0.000)$} & & & $55.27(43.00,67.54)$ & 100.00 \\
\hline
\end{tabular}

Figure 2. Forest plot of the pooled prevalence of home child-birth among reproductive-age women in Ethiopia, 2021. 


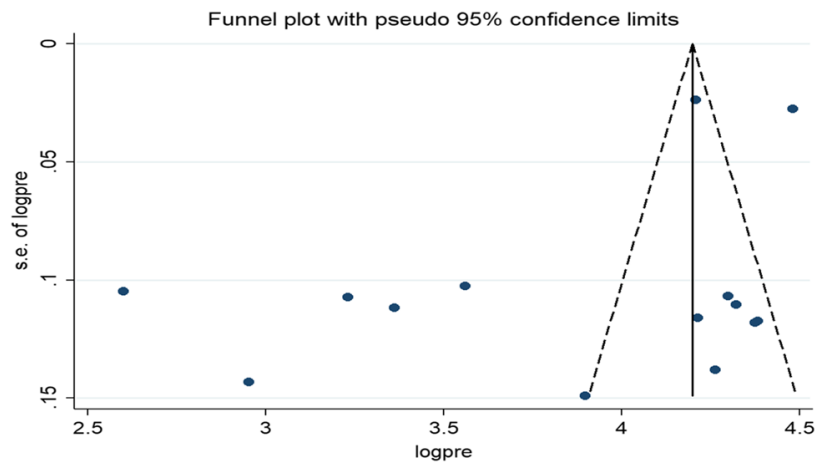

Figure 3. Funnel plot of the pooled prevalence of home child-birth among reproductive-age women in Ethiopia, 2021.

\begin{tabular}{|l|l|l|l|l|}
\hline Variables & Characteristics & Included studies & Estimate (95\% CI) & $\mathbf{I}^{\mathbf{2}} \mathbf{( \% )}$ \\
\hline \multirow{4}{*}{ Region } & Amhara & 3 & $45.2(14.9,75.5)$ & 99.5 \\
\cline { 2 - 5 } & SNNPR & 5 & $56.6(28.4,84.9)$ & 99.6 \\
\cline { 2 - 5 } & Others & 6 & $59.2(44,74.3)$ & 99.8 \\
\hline \multirow{3}{*}{ Residence } & Urban & 2 & $24(14.5,33.5)$ & 89.3 \\
\cline { 2 - 5 } & Rural & 3 & $67.6(52.6,82.6)$ & 97.2 \\
\cline { 2 - 5 } Sample size & Rural and urban & 9 & $58.1(43.4,72.9)$ & 99.8 \\
\cline { 2 - 6 } & $<500$ & 8 & $58.8(42.3,75.4)$ & 99.2 \\
\hline \multirow{2}{*}{ Study design } & Cross-sectional & 12 & $50.5(31.6,69.5)$ & 99.9 \\
\cline { 2 - 6 } & Cohort & 2 & $60.9(50.2,71.8)$ & 99.7 \\
\hline
\end{tabular}

Table 2. Subgroup prevalence of home child-birth among reproductive-age women in Ethiopia, $2021(\mathrm{n}=14)$. SNNPR-Southern Nation Nationalities and Peoples Region; others- Benishangul Gumuz, Tigray, Afar, Oromia and EDHS based.

\begin{tabular}{|l|l|l|}
\hline Variables & Coefficient & $\boldsymbol{P}$ value \\
\hline Sample size & 0.0028425 & 0.225 \\
\hline Study year & -2.668666 & 0.492 \\
\hline
\end{tabular}

Table 3. Univariate meta-regression analysis to determine factors related to the heterogeneity of the prevalence of home child-birth in Ethiopia, 2021.

\section{Discussion}

In this meta-analysis, the pooled prevalence of home child-birth among reproductive-age women in Ethiopia was $55.3 \%$ (95\% CI: 43, 67.5). Lack of ANC visit and unwanted pregnancy had a statistically significant association with home delivery.

The pooled prevalence of home child-birth was in line with a recently published systematic review and metaanalysis study $(66.7 \%)^{41}$. It is also in line with the 2019 mini Ethiopian Demographic and health survey report $(50 \%)^{19}$ and another study conducted in Tanzania $(65 \%)^{47}$. But, the finding was higher than studies conducted in $\operatorname{Nepal}(41.9 \%)^{48}$ and Burkina Faso $(11 \%)^{49}$. The possible explanations for the variation could be due to the differences in the maternal socioeconomic and educational status, accesses to the health facility, quality of health service, media exposure, and health-seeking behavior. The result of subgroup analysis showed the pooled prevalence of home child-birth was significantly higher among studies conducted in rural settings as compared to studies conducted in an urban setting. The finding is similar to a systematic review and meta-analysis study conducted in sub-Saharan Africa ${ }^{50}$. It is because women living in rural areas face financial constraints, and lack transport access and decision-making power to receive skilled delivery care ${ }^{51}$. The finding of this meta-analysis indicates how much it is too far to achieve national and international goals to end maternal and infant mortality ${ }^{20,24}$. Thus, it urges the national government and other responsible individuals to invest their valuable effort to address the problem of home child-birth among women in all areas of the nation.

In this meta-analysis, the likelihood of home child-birth was higher among women who had no ANC visit compared to ANC-booked women. Consistent findings were also reported from studies conducted in Zambia, Malawi, and Kenya ${ }^{52-54}$. Studies evidenced that factors that predispose women not to use ANC also make them 


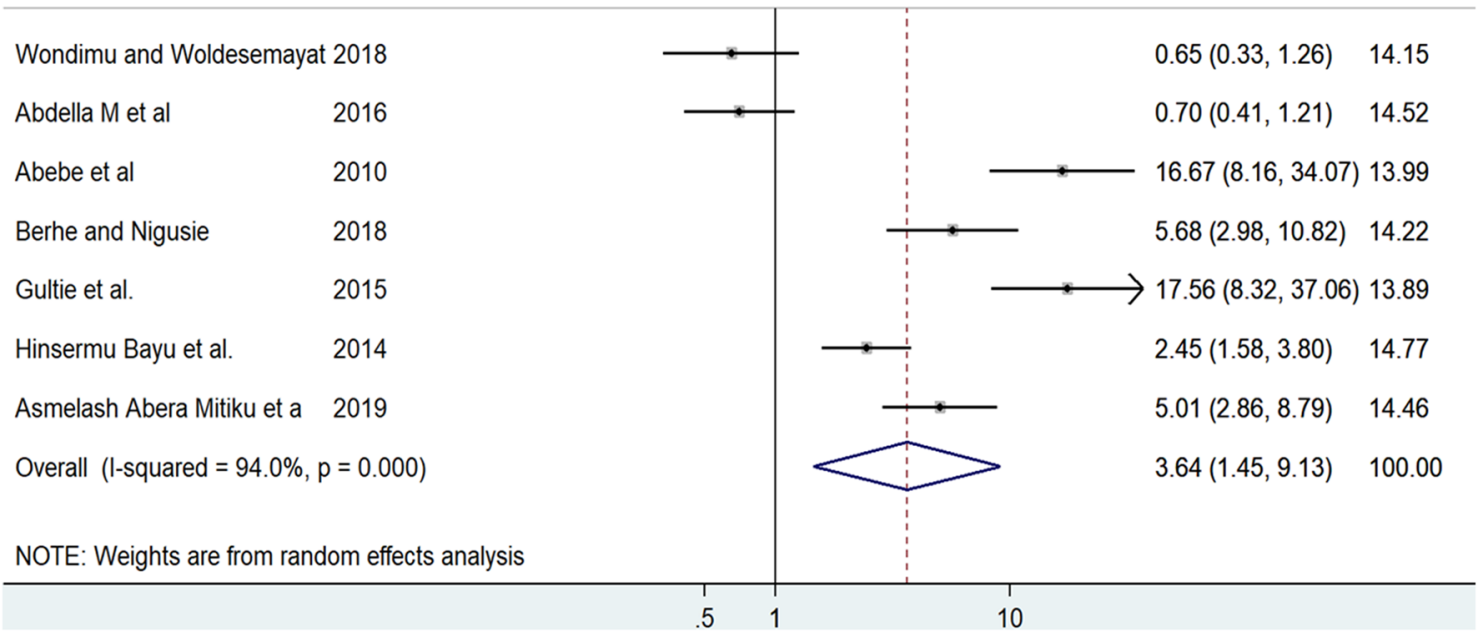

Figure 4. Forest plot of the pooled odds ratio of lack of ANC visit among reproductive age in Ethiopia, 2021.

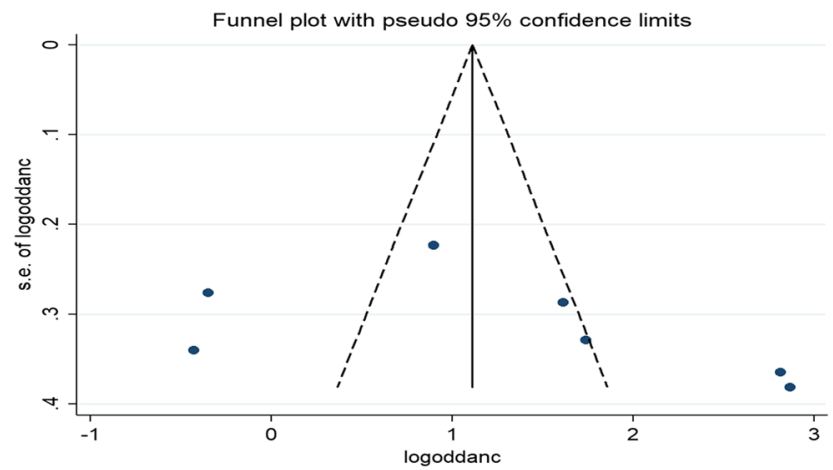

Figure 5. Funnel plot of the pooled odds ratio of lack of ANC visit among reproductive-age women in Ethiopia, 2021.

less likely to seek care during delivery ${ }^{55,56}$. ANC visit is the golden opportunity for pregnant women to discuss the place of delivery and to get information about the risks and complications encountered during pregnancy and delivery. A study conducted in Tanzania showed that women who are well informed about pregnancy complications during ANC visits are more likely to give birth in a health facility ${ }^{57}$. Failing to capitalize on ANC visits could be a significant missed opportunity to decrease maternal and neonatal mortality as a result of home delivery. Thus, clinicians need to promote the importance of ANC utilization to increase women's skilled delivery service utilization.

Unwanted pregnancy also had a positive association with home child-birth. It was in agreement with two studies conducted in Bangladesh ${ }^{58,59}$ and a study done in Zimbabwe ${ }^{60}$. A systematic review and meta-analysis conducted in low- and lower-middle-income countries showed that unwanted pregnancy was associated with a $25-39 \%$ reduction in the use of delivery care ${ }^{61}$. This could be because uncooperative and threatening behaviors from family members and sexual partners are common among women with an unwanted pregnancy and these might limit women's decision-making power and financial support which might have a negative impact on accessing institutional delivery services ${ }^{61,62}$. In addition, mothers with unwanted pregnancies may not worried about the health of the baby and might give less value to the expected child so that they do not seek delivery care utilization.

As a limitation, this systematic review and meta-analysis may not be representative of articles published in languages other than English. In addition, most of the included articles were cross-sectional and had a small sample size and thus might affect the pooled effect. Moreover, this meta-analysis may not be representative of all regions of Ethiopia. 
Authors

year

$\mathrm{OR}(95 \% \mathrm{Cl})$

Weight

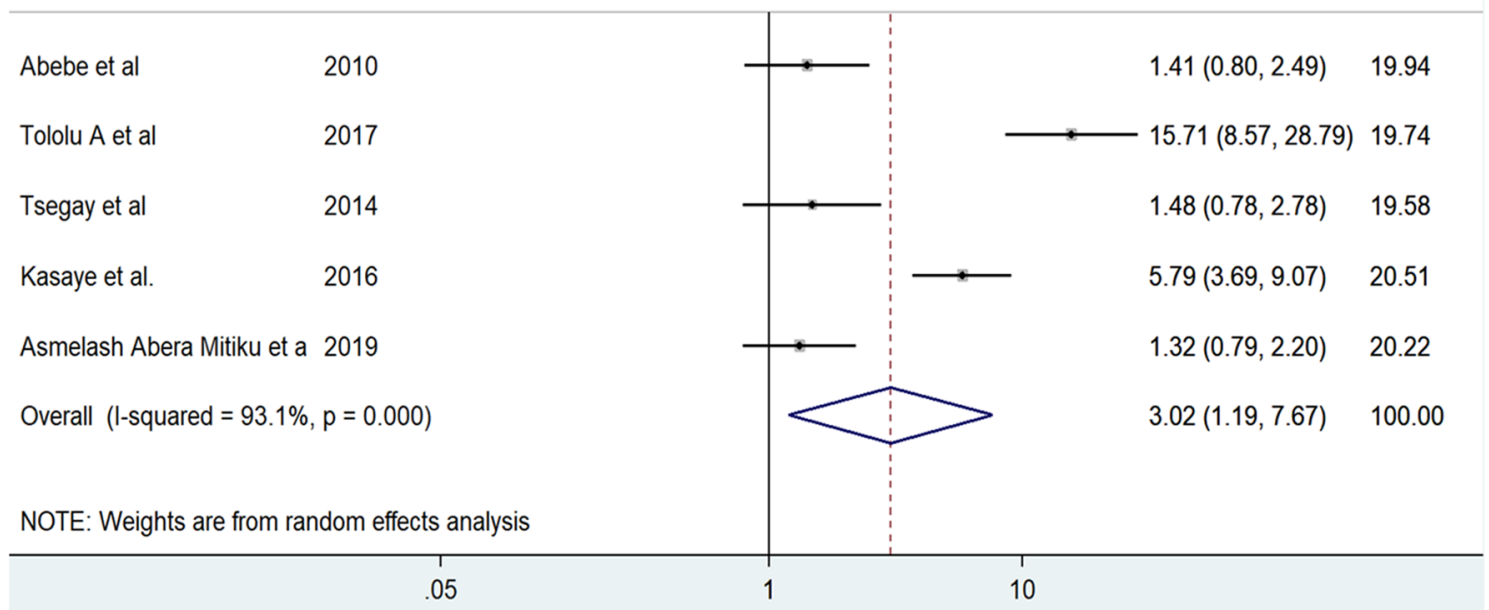

Figure 6. Forest plot of the pooled odds ratio of unwanted pregnancy among reproductive-age women in Ethiopia, 2021.

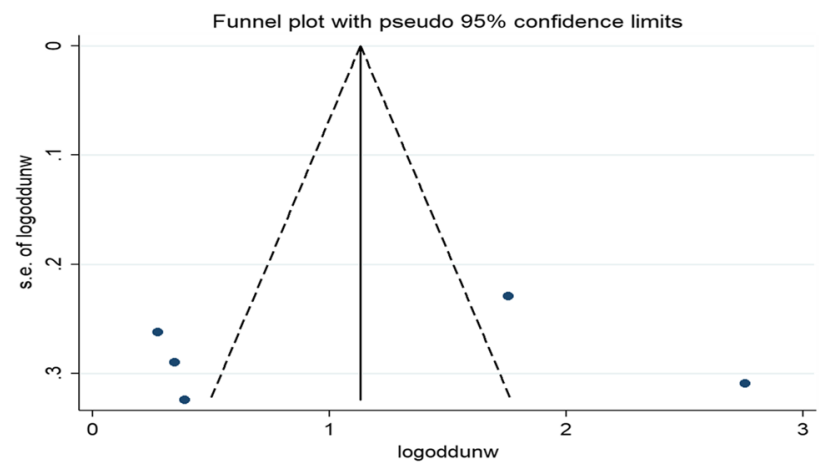

Figure 7. Funnel plot of the pooled odds ratio of unwanted pregnancy among reproductive-age women in Ethiopia, 2021.

\section{Conclusions}

The proportion of home child-birth in Ethiopia was considerably high. The lack of ANC visit and unwanted pregnancy had a significant effect on home delivery. Increasing the access to family planning services and strengthening the Information, Education and Communication (IEC) program is vital to decrease unwanted pregnancy and improve maternal health service utilization particularly ANC follow-up to make a home delivery-free community.

\section{Data availability}

The datasets used and/or analyzed during this study are available from the corresponding author on reasonable request.

Received: 18 June 2021; Accepted: 30 December 2021

Published online: 27 January 2022

\section{References}

1. Unfpa, W. H. O. The World Bank, United Nations Population Division. Trends in Maternal Mortality: 1990 to 2013 (WHO, Geneva, 2015).

2. Csace, I. Ethiopia demographic and health survey 2016 (CSA and ICF, Addis Ababa, 2016).

3. Abdella, A. Maternal mortality trend in Ethiopia. Ethiop. J. Health Dev. 2010;24(1).

4. Say, L. et al. Global causes of maternal death: a WHO systematic analysis. Lancet Glob. Health 2(6), e323-e333 (2014).

5. Harvey, S. A. et al. Skilled birth attendant competence: an initial assessment in four countries, and implications for the Safe Motherhood movement. Int. J. Gynecol. Obstet. 87(2), 203-210 (2004).

6. Rockers, P. C., Wilson, M. L., Mbaruku, G. \& Kruk, M. E. Source of antenatal care influences facility delivery in rural Tanzania: a population-based study. Matern. Child Health J. 13(6), 879-885 (2009). 
7. Kumbani, L., Bjune, G., Chirwa, E. \& Odland, J. Ø. Why some women fail to give birth at health facilities: a qualitative study of women's perceptions of perinatal care from rural Southern Malawi. Reprod. Health 10(1), 1-12 (2013).

8. Gultie, T., Wasihun, B., Kondale, M. \& Balcha, B. Home delivery and associated factors among reproductive-age women in Shashemene town Ethiopia. J. Women's Health Care. 5(300), 2167-2420 (2016).

9. Berhe, R. \& Nigusie, A. Magnitude of home delivery and associated factors among child-bearing age mothers in Sherkole District, Benishangul Gumuz regional state-Western-Ethiopia. BMC Public Health 20, 1-7 (2020).

10. Federal democratic republic of Ethiopia: Ministry of health. Addis Ababa, Ethiopia, 2006.

11. Wagle, R. R., Sabroe, S. \& Nielsen, B. B. Socioeconomic and physical distance to the maternity hospital as predictors for the place of delivery: an observation study from Nepal. BMC Pregnancy Childbirth 4(1), 1-10 (2004).

12. Abeje, G., Azage, M. \& Setegn, T. Factors associated with Institutional delivery service utilization among mothers in Bahir Dar City administration, Amhara region: a community-based cross-sectional study. Reprod. Health 11(1), 1-7 (2014).

13. Tarekegn, S. M., Lieberman, L. S. \& Giedraitis, V. Determinants of maternal health service utilization in Ethiopia: analysis of the 2011 Ethiopian Demographic and Health Survey. BMC Pregnancy Childbirth 14(1), 1-13 (2014).

14. Berhan, Y. \& Berhan, A. Antenatal care as a means of increasing birth in the health facility and reducing maternal mortality: a systematic review. Ethiop. J. Health Sci. 24, 93-104 (2014).

15. Yebyo, H., Alemayehu, M. \& Kahsay, A. Why do women deliver at home? Multilevel modeling of Ethiopian National Demographic and Health Survey data. PLoS One. 10(4), e0124718 (2015).

16. Celik, Y. \& Hotchkiss, D. R. The socio-economic determinants of maternal health care utilization in Turkey. Soc. Sci. Med. 50(12), 1797-806. https://doi.org/10.1016/S0277-9536(99)00418-9(2000).

17. Mayhew, M. et al. Determinants of skilled birth attendant utilization in Afghanistan: a cross-sectional study. Am. J. Public Health. 98(10), 1849-56. https://doi.org/10.2105/AJPH.2007.123471 (2008).

18. DelBarco, R. Monitoring birth preparedness and complication readiness. Tools and indicators for maternal and newborn health (Jhpiego, Baltimore, 2004).

19. CSA I. Ethiopia Mini Demographic and Health Survey 2019: key indicators report. Central statistics agency (CSA) [Ethiopia] and ICF. Addis Ababa: CSA and ICF. 2019.

20. Ministry of Health. Ethiopian Health Sector Transformation Plan. 2015/16-2019/20.

21. Teferra, A. S., Alemu, F. M. \& Woldeyohannes, S. M. Institutional delivery service utilization and associated factors among mothers who gave birth in the last 12 months in Sekela District, North West of Ethiopia: A community-based cross-sectional study. BMC Pregnancy Childbirth 12(1), 1-11 (2012).

22. Nigatu, A. M. \& Gelaye, K. A. Factors associated with the preference of institutional delivery after antenatal care attendance in Northwest Ethiopia. BMC Health Serv. Res. 19(1), 1-9 (2019).

23. Magadi, M., Diamond, I. \& Rodrigues, R. N. The determinants of delivery care in Kenya. Soc. Biol. 47(3-4), 164-188 (2000).

24. Assembly G. Sustainable development goals. SDGs Transform Our World. 2015;2030.

25. Ibrahim, S., Handiso, T., Jifar, M., Yoseph, E. Analyzing prevalence of home delivery and associated factors in Anlemo District, Southern Ethiopia. Int Ann Med. 2017;1(6).

26. Ayele, G., Tilahune, M., Merdikyos, B., Animaw, W. \& Taye, W. Prevalence and associated factors of home delivery in Arbaminch Zuria district, southern Ethiopia: a community-based cross-sectional study. Science 3(1), 6-9 (2015).

27. Abdella, M., Abraha, A., Gebre, A. \& Reddy, P. S. The magnitude and associated factors for home delivery among women who gave birth in last 12 months in Ayssaita, Afar, Ethiopia-2016. A community-based cross-sectional study. Glob. J. Fertil. Res. 2(1), 030-9 (2017).

28. Abebe, F., Berhane, Y. \& Girma, B. Factors associated with home delivery in Bahirdar, Ethiopia: a case-control study. BMC. Res. Notes 5(1), 1-6 (2012).

29. Tololu, A.K., Massa, M.G., Kerie, M.W., Misgina, K.H., Alema, H.B., Weldu, M.G. Determinants of home delivery in the central zone of Tigrai, North Ethiopia: Evidence from case-control study. 2020.

30. Kasaye, H. K., Endale, Z. M., Gudayu, T. W. \& Desta, M. S. Home delivery among antenatal care booked women in their last pregnancy and associated factors: a community-based cross-sectional study in Debremarkos town, North West Ethiopia, January 2016. BMC Pregnancy Childbirth 17(1), 1-12 (2017).

31. Wodaynew, T., Fekecha, B. \& Abdisa, B. Magnitude of home delivery and associated factors among antenatal care booked mothers in Delanta District, South Wollo Zone, North East Ethiopia: a cross-sectional study, March 2018. Int. J. Women's Health Wellness. 4(2), 1-11 (2018).

32. Chernet, A. G., Dumga, K. T. \& Cherie, K. T. Home delivery practices and associated factors in Ethiopia. J. Reprod. Infertility. 20(2), $102(2019)$

33. Mitiku, A.A., Dimore, A.L., Mogas, S.B. Determinants of home delivery among mothers in Abobo District, Gambella Region, Ethiopia: A case-control study. Int. J. Reprod. Med. 2020.

34. Mekonnen, Y., Ayichiluhm, M. \& Dejenu, G. Prevalence and determinants of home birth after antenatal care attendance in Gozamin District, Northwest Ethiopia. Health Sci. J. 9(6), 1 (2015).

35. Delibo, D., Damena, M., Gobena, T., Balcha, B. Status of home delivery and its associated factors among women who gave birth within the last 12 months in East Badawacho District, Hadiya Zone, Southern Ethiopia. BioMed Res. Int.. 2020;2020.

36. Wondimu, M. S. \& Woldesemayat, E. M. Determinants of home delivery among women in rural pastoralist community of Hamar District, Southern Ethiopia: A case-control study. Risk Manag. Healthcare Policy. 13, 2159 (2020).

37. Tsegay, R., Aregay, A., Kidanu, K., Alemayehu, M. \& Yohannes, G. Determinant factors of home delivery among women in Northern Ethiopia: a case-control study. BMC Public Health 17(1), 1-8 (2017).

38. Bayu, H., Fisseha, G., Mulat, A., Yitayih, G. \& Wolday, M. Missed opportunities for institutional delivery and associated factors among urban resident pregnant women in South Tigray Zone, Ethiopia: a community-based follow-up study. Glob. Health Action 8(1), 28082 (2015).

39. Siyoum, M. et al. Homebirth and its determinants among antenatal care-booked women in public hospitals in Wolayta Zone, southern Ethiopia. PloS one. 13(9), e0203609 (2018).

40. Kucho, B. \& Mekonnen, N. Delivery at home and associated factors among women in childbearing age, who gave birth in the preceding two years in Zala Woreda, southern Ethiopia. J. Public Health Epidemiol. 9(6), 177-188 (2017).

41. Ayenew, A. A., Nigussie, A. A. \& Zewdu, B. F. Childbirth at home and associated factors in Ethiopia: a systematic review and meta-analysis. Arch. Public Health. 79(1), 1-8 (2021).

42. Moher, D., Liberati, A. A., Tetzlaff, J. \& Altman, D. G. Preferred reporting items for systematic reviews and meta-analyses: the PRISMA statement. BMJ. 339, b2535 (2009).

43. Moola, S., Munn, Z., Tufanaru, C., Aromataris, E., Sears, K., Sfetcu, R., et al. Chapter 7: Systematic reviews of etiology and risk. Joanna Briggs Institute Reviewer's Manual The Joanna Briggs Institute. 2017;5.

44. DerSimonian, R. \& Laird, N. Meta-analysis in clinical trials revisited. Contemp. Clin. Trials 45, 139-145 (2015).

45. Egger, M., Smith, G. D., Schneider, M. \& Minder, C. Bias in meta-analysis detected by a simple, graphical test. BMJ 315(7109), 629-634 (1997).

46. Duval, S. \& Tweedie, R. Trim and fill: a simple funnel-plot-based method of testing and adjusting for publication bias in metaanalysis. Biometrics 56(2), 455-463 (2000). 
47. Simfukwe, M. Factors contributing to home delivery in Kongwa District, Dodoma-September 2008. Dar Es Salaam Med. Stud. J.. 18(1), 13-22 (2011).

48. Dhakal, P., Shrestha, M., Baral, D. \& Pathak, S. Factors affecting the place of delivery among mothers residing in Jhorahat VDC, Morang Nepal. Int. J. Commun. Based Nurs. Midwifery. 6(1), 2 (2018).

49. De Allegri, M. et al. Understanding home delivery in a context of user fee reduction: cross-sectional mixed methods study in rural Burkina Faso. BMC Pregnancy Childbirth 15(1), 1-13 (2015).

50. Wong, K. L., Benova, L. \& Campbell, O. M. A look back on how far to walk: systematic review and meta-analysis of physical access to skilled care for childbirth in sub-Saharan Africa. PloS one. 12(9), e0184432 (2017).

51. Chakrborty, N., Islam, M. A., Chowdhurg, R. I. \& Bori, W. Determinants of the use of maternal Health service in rural Bangladesh. Health Promot Int 18(4), 327-337 (2005).

52. Scott, N. A. et al. Factors affecting home delivery among women living in remote areas of rural Zambia: a cross-sectional, mixedmethods analysis. Int. J. Women's Health 10, 589 (2018).

53. Palamuleni, M. Determinants of non-institutional deliveries in Malawi. Malawi Med. J. 23(4), 104-108 (2011).

54. Kitui, J., Lewis, S. \& Davey, G. Factors influencing place of delivery for women in Kenya: an analysis of the Kenya demographic and health survey, 2008/2009. BMC Pregnancy Childbirth 13(1), 1-10 (2013).

55. Nair, M., Ariana, P., Webster, P. What influences the decision to undergo institutional delivery by skilled birth attendants? A cohort study in rural Andhra Pradesh, India. 2012.

56. Stephenson, R., Baschieri, A., Clements, S., Hennink, M. \& Madise, N. Contextual influences on modern contraceptive use in sub-Saharan Africa. Am. J. Public Health 97(7), 1233-1240 (2007).

57. Mpembeni, R. N. et al. Use pattern of maternal health services and determinants of skilled care during delivery in Southern Tanzania: implications for achievement of MDG-5 targets. BMC Pregnancy Childbirth 7(1), 1-7 (2007).

58. Khan, M.N., Harris, M.L., Loxton, D. Does unintended pregnancy have an impact on skilled delivery care use in Bangladesh? A nationally representative cross-sectional study using Demography and Health Survey data. J. Biosoc. Sci. 2020:1-17.

59. Rahman, M. M., Rahman, M. M., Tareque, M. I., Ferdos, J. \& Jesmin, S. S. Maternal pregnancy intention and professional antenatal care utilization in Bangladesh: a nationwide population-based survey. PloS one. 11(6), e0157760 (2016).

60. Muchabaiwa, L., Mazambani, D., Chigusiwa, L., Bindu, S. \& Mudavanhu, V. Determinants of maternal healthcare utilization in Zimbabwe. Int. J. Econ. Sci. Appl. Res. 5(2), 145-162 (2012).

61. Khan, M. N., Harris, M. L., Shifti, D. M., Laar, A. S. \& Loxton, D. Effects of unintended pregnancy on maternal healthcare services utilization in low-and lower-middle-income countries: systematic review and meta-analysis. Int. J. Public Health 64(5), 743-754 (2019).

62. Dahiru, T., Oche, O.M. Determinants of antenatal care, institutional delivery and postnatal care services utilization in Nigeria. Pan Afr. Med. J. 2015;22(1).

\section{Acknowledgements}

The authors would like to thank all public health staff for their help when needed and Wollo University library for providing an available online database.

\section{Author's contributions}

Y.D. involved in the conception of a research protocol, literature review, study design, data extraction, data analysis, and interpretation; B.K., M.Y., N.C. and M.A. involved in literature review and screening; T.B., E.T., G.B., W.M., A.A., E.A. and B.A. undertake data extraction and quality assessment; R.D. and B.K. involved in the drafting of the manuscript; G.B., A.A., and M.A. involved in reviewing the manuscript. All authors have read and approved the manuscript.

\section{Competing interests}

The authors declare no competing interests.

\section{Additional information}

Supplementary Information The online version contains supplementary material available at https://doi.org/ 10.1038/s41598-022-05260-5.

Correspondence and requests for materials should be addressed to Y.D.

Reprints and permissions information is available at www.nature.com/reprints.

Publisher's note Springer Nature remains neutral with regard to jurisdictional claims in published maps and institutional affiliations.

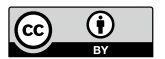

Open Access This article is licensed under a Creative Commons Attribution 4.0 International License, which permits use, sharing, adaptation, distribution and reproduction in any medium or format, as long as you give appropriate credit to the original author(s) and the source, provide a link to the Creative Commons licence, and indicate if changes were made. The images or other third party material in this article are included in the article's Creative Commons licence, unless indicated otherwise in a credit line to the material. If material is not included in the article's Creative Commons licence and your intended use is not permitted by statutory regulation or exceeds the permitted use, you will need to obtain permission directly from the copyright holder. To view a copy of this licence, visit http://creativecommons.org/licenses/by/4.0/.

(C) The Author(s) 2022 